This is a pre-copy-editing, author-produced PDF of an article accepted for publication in ICES Journal of Marine Science following peer review. The definitive publisher-authenticated version Cogan, C. B., Todd, B. J., Lawton, P., and Noji, T. T. 2009. The role of marine habitat mapping in ecosystem-based management. ICES Journal of Marine Science, 66: 2033-2042 is available online at:

http://icesjms.oxfordjournals.org/cgi/content/short/66/9/2033

\title{
The role of marine habitat mapping in ecosystem-based management
}

\author{
Christopher B. Cogan, Brian J. Todd, Peter Lawton, and Thomas T. Noji
}

C. B. Cogan: Environmental Science and Resource Management, California State University Channel Islands, 1 University Drive, Camarillo, CA 93012, USA.

B. J. Todd: Geological Survey of Canada (Atlantic), Natural Resources Canada, Bedford Institute of Oceanography, 1 Challenger Drive, Dartmouth, NS, Canada B2Y 4A2.

P. Lawton: Fisheries and Oceans Canada, Science Branch, Maritimes Region, Biological Station, 531 Brandy Cove Road, St Andrews, NB, Canada E5B 2L9.

T. T. Noji: US Department of Commerce, NOAA Fisheries, Northeast Fisheries Science Center, James J. Howard Marine Sciences Laboratory, 74 Magruder Road, Sandy Hook, NJ 07732, USA.

\section{Abstract:}

Ecosystem-based management (EBM) and the related concept of large marine ecosystems (LMEs) are sometimes criticized as being too broad for many management and research applications. At the same time there is a great need to more effectively develop substantive scientific methods to empower EBM. Marine habitat mapping (MHM) is one example of an applied set of field methods that directly support EBM and contribute essential elements for conducting integrated ecosystem assessments. This paper places MHM practices in context with biodiversity models and EBM. We build the case for MHM being incorporated as an explicit and early process following initial goal setting within larger EBM programs. Advances in MHM and EBM are dependent on evolving technological and modeling capabilities, conservation targets, and policy priorities within a spatial planning framework. In both cases, the evolving and adaptive nature of these sciences requires explicit spatial parameters, clear objectives, combinations of social and scientific considerations, and multiple parameters to assess overlapping viewpoints and ecosystem functions. To examine the commonalities between MHM and EBM, we also address issues of implicit and explicit 
linkages between classification, mapping, and elements of biodiversity with management goals. Policy objectives such as sustainability, ecosystem health, or the design of marine protected areas are also placed in the combined MHM-EBM context.

Keywords: biodiversity, ecosystem, GIS, habitat, management, mapping, marine

Acknowledgements to the ICES Working Group on Marine Habitat Mapping, and the Alfred Wegener Institute for Polar and Marine Research, Bremerhaven, Germany. The authors also wish to acknowledge the helpful reviews by Jake Rice (Fisheries and Oceans Canada), Roger L. Parsons (National Oceanic and Atmospheric Administration), and Michael Jennings (The Nature Conservancy).

Introduction

Ecosystem-based management (EBM) and the often similar "ecosystem approach to management (EAM) represent effective and much needed approaches to conserve and manage marine systems (De Young et al., 2008). With increasing pressures from a growing human population, we are depleting the natural capital from the world's marine ecosystems and altering habitats in ways we are only recently able to measure and monitor. Parallel with developments in terrestrial ecology, the concepts of marine EBM can be tied to the writings of Aldo Leopold in the 1940s (Leopold, 1941, Leopold, 1949), the development of modern biodiversity initiatives such as the Convention on Biodiversity (United Nations Environment Programme, 1992), and actions such as the U.S. Sustainable Fisheries Act of 1996 and the recent reauthorization (2006) of the Magnuson-Stevens Fishery Conservation and 
Management Act. Recent publications calling for an increased pace of marine EBM include the Pew Oceans Commission report (2003), the U.S. Commission on Ocean Policy report (2004), the Millennium Ecosystem Assessment (2005), a Scientific Consensus Statement on Marine Ecosystem-based Management (McLeod et al., 2005) and the Food and Agriculture Organization of the United Nations (FAO) Fisheries Technical Paper on the ecosystem approach to fisheries (Garcia et al., 2003).

Unfortunately, while the urgent need for EBM is widely acknowledged, and efforts such as the EU Marine Strategy Framework Directive (European Parliament, 2008) and the Australian sustainable fisheries guidelines (Anonymous, 2001) offer encouraging progress, EBM is seldom fully implemented. This may be due to political and administrative bottlenecks (Young et al., 2007) which restrict implementation beyond the conceptual level (Ehler and Douvere, 2007), or we may simply be in the early stages of EBM adoption and only require better coordination among sectors (Murawski, 2007). EBM, as with the ecosystems it addresses, is a complex entity, involving a set of interconnected concepts, disciplinary approaches, and technical issues that must be interpreted, synthesized, and communicated across an extended community of scientists, policy makers and stakeholders. Clarifying the context, opportunities, constraints, and contributions of specific components of EBM will foster communication and help to avoid the mistaken appearance of insurmountable complexity.

In this paper, we deconstruct the key components of EBM, building on previous theory from the ecological and marine science literature. Our focus is on EBM of marine systems, however our examples and conclusions do have terrestrial analogues. By working with separate EBM components, we present a new perspective on the position and role of marine 
habitat mapping (MHM) within EBM frameworks. We also establish key guidelines for using MHM effectively in managing human interactions within the natural complexity of marine ecosystems.

To promote EBM - and to clarify how its concepts are communicated - Grumbine (1994) conducted one of the first surveys to identify the dominant themes and major goals of EBM. The goals of EBM are broad-reaching, encompassing viable populations, representation, ecological process, management, and the role of humans in ecosystems (Table 1). Although there is not universal agreement that these goals are achievable (e.g. Larkin, 1996), Grumbine’s landmark paper nonetheless set the stage for modern approaches to marine EBM, including the Food and Agricultural Organization (FAO) Code of Conduct (FAO, 1995, FAO, 2008) and guidelines for marine management in accordance with the Convention on Biological Diversity (AIDEnvironment et al., 2004). Building on the major themes outlined by Grumbine and many other subsequent authors including Christensen (1996), there is now general agreement on a working definition of EBM covering both marine and terrestrial applications (Table 2).

In spite of the overwhelming evidence that marine EBM is needed, and that we are now poised to combine science and policy to undertake greatly improved marine management practices, EBM applications are not trouble-free. As one example, EBM and the related concept of large marine ecosystems (LMEs) used to categorize ecological management units are sometimes criticized as being too broad to allow any "real progress” in management (Longhurst, 2003). In addition, technological challenges remain, thereby emphasizing the need to develop more effective "tool kits” to empower EBM (Tudela and Short, 2005), and governance issues exist when working with wide-ranging ecosystem scales (Young et al., 
2007). To help alleviate some of these criticisms and concerns over methodological approaches, it is helpful to place EBM in context with examples of ongoing research and management, and show how existing methods and organizational guidelines are - when carefully planned - solid examples of marine EBM. In a general form, this comparison has been introduced by Murawski (2007) but here we focus on the specific science and management elements. Early-on, Grumbine (1994) described EBM as a "reframing”, forecasting our current evolution rather than revolution in marine management practices. Indeed, even the methods employed by the pioneering scientists of the Challenger Expedition (1872-1876) directly supported marine EBM by providing nearly 30,000 pages of descriptive text on the worlds oceans. What is now beneficial is a rethinking as to how our existing data and methods can be applied to best support a management strategy that is ecosystem-based.

I) Rethinking Marine Habitat Mapping as a Launch Point for Marine Ecosystem-Based Management

One of the first steps following the establishment of EBM goals (Table 1) should be to characterize the habitat features of the ecosystem. As with habitat mapping in terrestrial ecology, marine habitat mapping (MHM) is a powerful approach to support modeling and management of marine ecosystems. Marine habitat mapping is becoming a standard activity in surveys of both national waters and international areas of interest. However, it has not been commonplace to associate individual MHM efforts with EBM. The process of MHM includes interpretation and classification of ship-based acoustic mapping of depth, substrate, and geomorphology, in addition to satellite-based surface measures of roughness, currents, temperature, and productivity. Each of these measures are further associated with local 
sampling surveys. With a close look at the relationships between the activities of MHM and the goals of EBM, we can not only - as Grumbine suggests - "reframe” and refine our mapping activities, but at the same time we can document the initial condition for EBM and therefore more efficiently prepare for its implementation. In this sense, MHM is part of a logical sequence within EBM. While differences in specific objectives will exist from one research project to another, a general approach to marine EBM places MHM early in the process followed by evaluations of biodiversity, functional processes, and the development of management procedures (Figure 1).

Notably, the implementation of a new multiagency U.S. initiative, the National Fish Habitat Action Plan (Association of Fish and Wildlife Agencies, 2006) reflects the essential role of MHM for EBM. In response to a need to conserve fish habitat to promote sustainable fisheries and conserve biodiversity, several U.S. Departments and Agencies formed an alliance to tackle this problem. After two years of consultations with experts and stakeholders, the first phase of research activities involves two main components: (1) aquatic habitat mapping and classification and (2) habitat condition modeling, whereby key components in the modeling include an index of biological integrity (closely related to biodiversity) and anthropogenic stressors. The findings from this research phase will be used within the context of EBM to establish conservation and restoration measures. This pattern of habitat classification, mapping, and modeling is increasingly used for marine management. The European Nature Information System (EUNIS), is another example where hierarchal habitat types are mapped and integrated with species data and site data to support management decisions such as protected area design under the Natura 2000 program of the European Commission. 
In support of the premise that habitat mapping in marine systems is a logical starting point for marine EBM, we outline here the correspondence between the dominant themes of EBM and the practice of MHM. In addition to articulating the general goals of EBM, the review paper by Grumbine (1994) outlines a series of ten dominant themes for EBM. These and similar characterizations of EBM have since been reinforced in the terrestrial and marine literature by many authors including an historic overview and call for increased application of EBM by Christensen et al. (1996), a "Scientific Consensus Statement on Marine EcosystemBased Management” (McLeod et al., 2005), a survey paper by Arkema et al. (2006), and a paper on the challenges of marine EBM by Ruckelshaus et al. (2008). While mappingmanagement connections are of general interest, and show that MHM is an important element of EBM, more important are the insights that can be gained by deconstructing this combination of MHM and EBM to show the potential improvements from this synergistic combination. Conversely, MHM that is conducted without explicit consideration for the elements of EBM is likely to fall short of its potential. Below is a point-by-point comparison between all ten of the specific elements originally proposed by Grumbine (1994) for EBM and the corresponding characteristics of a well-planned MHM program.

1) Hierarchical Context. It is important to conduct EBM such that connections between thematic, temporal, and spatial scales are addressed. For example, studies at the species, community, or ecoregional extent can be integrated as a hierarchy to strengthen individual results. One of the most straightforward methods for documenting spatial grain and extent as well as corresponding habitat homogeneity is through the use of habitat maps. In MHM, this is achieved through a combination of mapping techniques including broad-scale satellite 
quantification of the ocean surface (e.g. Hardman-Mountford et al., 2008), medium-grain acoustic surveys of the benthos, and high-resolution photo transects. In some cases, when working with large previously unmapped areas, combinations of MHM and environmental modeling are also employed (Pickrill and Kostylev, 2007).

2) Ecological Boundaries. A key element of EBM is the recognition that species distributions and derived ecological boundaries, and not administrative or political boundaries, should guide marine management. Because ecological boundaries are largely documented through the marine mapping process, it is particularly critical that the mapping areas, techniques used, and classification concepts are consistent within the framework of large marine ecosystems (LMEs). Global examples of marine ecoregion mapping include the “GOOD’s” open oceans classification (Vierros et al., 2008), and the coastal shelf "Marine Ecoregions of the World" (MEOW) (Spalding et al., 2007). With such frameworks in place, consistently mapped ecological boundaries and zones can be used to support both specific applications such as sea use management and marine spatial planning (Ehler and Douvere, 2007) as well as EBM. This approach to MHM has already been successfully implemented in several ecoregions, including the development of consistent acoustic mapping methods across U.S. - Canadian national boundaries in the Gulf of Maine (Valentine et al., 2005). Recent European examples include mapping activities by a consortium of northwest European nations (MESH (Mapping European Seabed Habitat), 2008).

3) Ecological Integrity. Ecological integrity was clearly an important consideration for Leopold (1949) who wrote of the "integrity, stability, and beauty of the biotic community." 
More specifically, integrity is now considered to be the "capability of supporting and maintaining a balanced, integrated, adaptive community of organisms having a species composition, diversity, and functional organization comparable to that of natural habitat in the region" (Karr and Dudley, 1981). Andreasen and O’Neill et al. (2001) further characterize integrity as an index of "wholeness, completeness, and intactness" which can be compared to measures of "natural reference conditions" (Mattson and Angermeier, 2007). In quantifying ecological integrity, it is useful to consider this ecosystem attribute as a series of measures of total native diversity - including species composition, population dynamics, and ecosystem diversity - each of which have appropriate spatial scales for sustainable management over time (Norton and Ulanowicz, 1992). Although ecological integrity measures will require a wide range of habitat parameters, MHM specifically supports these measures by targeting the relationship between physiographic (e.g. sea floor bathymetry and substrate) and biological habitat requirements. By designing MHM to incorporate integrity parameters, MHM provides the foundation for species-habitat models and provides the basis for the quantitative analysis of structural, functional, and compositional biodiversity. One such MHM study was conducted off southwest Nova Scotia, where a sea scallop fishery is being effectively managed based in part on sea floor mapping surveys (Smith, 2006). Repeat mapping in such temporally dynamic areas facilitates monitoring and management of the fisheries, benefiting integrity by reducing bycatch and damage to epibenthic communities.

4) Data Collection. Habitat inventory and classification, measures of disturbance regime dynamics, baseline species and population assessments all require fundamental data collection. MHM integrates physical sampling, satellite, aircraft, and shipboard remote 
sensing data, surface water analysis, and pelagic and benthic observations into a common framework, often using geographic information systems (GIS) for data organization as well as spatial analysis. With appropriate planning, MHM acts to integrate a variety of data types, often making possible the otherwise challenging consolidation of information from differing spatial, temporal, and thematic scales. Furthermore, the wide range of data types integrated into GIS and consolidated across spatial scales is ideal to address multiple scientific objectives, extending our ability to extract information from basic data, and facilitating data synthesis for a broad range of research and EBM needs.

5) Monitoring. Monitoring allows us to identify and track "normal” temporal dynamics, and thus the consequences and efficacy of management operations. As with other change detection approaches common to remote sensing, benthic habitat maps as well as maps of sea surface condition portray many kinds of structural and compositional change. While there are many spatial and non-spatial metrics to evaluate integrity or quantify biodiversity, by highlighting areas of change, more detailed investigations can be prioritized to determine management priorities and recommended actions. Change detection based on MHM baselines are a logical and efficient part of EBM. The International Council for the Exploration of the Seas (ICES) North Sea Benthos Survey (Rees et al., 2007) is an example of repeated benthic monitoring which has led to management advice for the development of a research plan on the effects of broad scale hydrographic (i.e. temperature and salinity) changes on biota in the North Sea. 
6) Adaptive Management. Recognizing that our knowledge of marine ecosystems is provisional, it is widely recognized that EBM should incorporate feedbacks from ecosystem monitoring and be able to adapt management policies to work from new understandings or changing conditions (Christensen et al., 1996). Using existing MHM techniques, the process of mapping and monitoring provides a consistent ecosystem-wide approach to determine when management changes are needed. Examples of adaptive management in marine ecosystems could include, for example, changes in practices resulting from monitoring sea floor recovery following trawl operations.

7) Interagency Cooperation. For the same reasons ecological boundaries are advantageous over political boundaries when working with ecosystems, it is also logical that the various governing bodies within the framework of large marine ecosystems will need to cooperate to be effective. Common MHM data, based on ecological boundaries facilitates cooperation across agencies, departments, and intergovernmental organizations (IGO’s) by providing common scientific data and advice for a range of sectoral efforts. Examples of MHM at the multi-national level demonstrate the feasibility of intergovernmental cooperation, including a five country MHM program being conducted in northwest Europe (Coggan et al., 2005), and Canada-U.S. partnerships to map the Gulf of Maine (Noji et al., 2004). There are also numerous examples of interagency cooperation within national governments such as those in Australia (Harris et al., 2002, Porter-Smith et al., 2004), the National Fish Habitat Action Plan in the U.S. (Association of Fish and Wildlife Agencies, 2006); and an MOU between the U.S. Geological Survey (USGS) and the National Oceanic and Atmospheric Administration (NOAA) to coordinate and cooperate in activities involving physical sciences, biological 
sciences, and environmental studies (U.S. Department of the Interior and U.S. Department of Commerce, 2005).

8) Organizational Change. In addition to interagency cooperation, the recognized need for MHM and EBM has also acted to promote organizational change within agencies responsible for managing marine ecosystems. This change has cut across many levels of government, with entirely new divisions created to fulfill the EBM mandate. NOAA, for example, established an Ecosystems Goal Team consisting of nine programs with broad national participation from offices throughout the agency. The programs include Coastal and Marine Resources, Habitat, Ecosystems Observations, Ecosystems Research and others, all with MHM an important part of their mission. MHM is well positioned to help make these organizational changes successful by providing a consistent data source which directly supports interdisciplinary research and biodiversity assessment. For each management group, standardized structural information derived from multibeam hydroacoustic maps of the benthos and other physical science measures such as temperature, salinity, and currents provide a foundation from which to build biodiversity knowledge by integration with biological composition and ecosystem function.

9) Humans Embedded in Nature. It has long been recognized that human factors are of fundamental importance to ecosystems and that humans are in turn affected by them (Leopold, 1941, Rapport, 1998, Callicott, 2000). In this sense, humans are integral components of marine ecosystems. Habitat mapping with biodiversity assessment in marine systems is a primary approach to measure and monitor habitat alteration by fisheries, coastal 
and offshore development, aquaculture, aggregate mining, oil and gas extraction, military acoustics, and other direct anthropogenic effects. MHM is also a critical tool for detecting less obvious changes to marine ecosystems by providing the observational basis to characterize the effects of climate change, and providing policy makers with critical timeseries information to support regulatory modifications. In addition to mapping and modeling various ecosystem parameters, it is also possible to measure how humans interact with their environment as the ecosystem changes. As just one example of this expanding area of research, the Science Plan for Arctic Coastal Processes recently established a combined program of habitat mapping integrated with social science expertise as a funding priority for the international Arctic coastal zone (Cogan and Rachold, 2007). By quantifying anthropogenic (e.g., fisheries) effects, “natural” (e.g., ice flow) processes, and social interactions with ecosystems, MHM is well positioned to move "beyond bathymetry" supporting the inclusion of human elements in EBM.

10) Values. Perhaps the most important overarching theme of EBM is our changing attitude for valuing ecosystems. Sociocultural and economic factors are fundamental marine policy drivers. In essence, how people value marine ecosystems ultimately guides policy, and can result in organizational changes for the empowerment of EBM. Public perceptions and values depend, however, on a series of feedbacks. These include spiritual and aesthetic values, scientific information, measures of productivity such as goods and services (e.g., fisheries), policy, and regulation. As societies shift from a perspective of marine ecosystems as exploitable resources to one of sustainable management of ecosystem capital, stakeholders and policymakers alike require more extensive standardized and accessible information on 
different ecosystem components, as well as techniques to visualize the implications of alternative management strategies. Understanding and accessing multiple mapped layers of information that can be provided by MHM for the valuation of marine ecosystems is facilitated by geographic information systems.

One of the strongest tools for communicating the status of marine ecosystems is the map. MHM provides the means to visualize marine habitats. For policy makers and society in general, marine habitats are often out of sight - and out of mind. Producing "pictures" in the form of habitat maps builds public awareness, enhances general knowledge of the marine spatial landscape, and provides a starting place, or entry point, for values that can then be more fully developed. Maps, like pictures, are often worth a thousand words and offer a medium for quickly communicating environmental status with a minimum of technical jargon. As demonstrated by the now famous "earthrise over the lunar horizon" photo from Apollo 8 (NASA, 1968), images facilitate public engagement with ecosystems. In addition to the fundamental power of marine habitat images, a series of marine habitat maps that follow in the footsteps of nationally standardized terrestrial topographic maps provide a combination of photo-realistic imagery and cartographically accurate base maps for spatial analysis with geographic information systems (Figure 2, and see also Pickrill and Kostylev, 2007). In this sense, the fundamental product of MHM serves two needs - images to promote public engagement with marine ecosystems and, at the same time, a critical data set for EBM.

Directly supporting each of the ten principal elements of EBM, MHM brings new focus to the power of marine habitat maps and provides a pathway for the biological and ecological sciences to support urgently needed advances in management. Discrete spatial data themes 
that build into habitat maps represent ecological processes at multiple spatial and temporal scales. Maintaining individual map layers as model parameters provides the transparency, flexibility, and analytical power needed to proceed with ecosystem-based approaches. As specific types of data are collected and synthesized into map layers, the ten MHM/EBM elements can help guide data collection methods. Rather than a unidirectional methodology to gather, aggregate, and generalize complexes of ecosystem data, we will be increasingly challenged to interpret individual components. This deconstruction of our maps and data models can better support transparency and flexibility, while at the same time supporting new combinations of our data to represent the big picture. Keeping the parts while building the whole is challenging, but our deconstruction and linkages between MHM and EBM offer a way forward to achieve this. At the same time, investigations of discrete marine habitat elements and their interconnections to EBM sheds new light on the interconnections between habitat classification, mapping, biodiversity, and management.

II) Design Considerations and Needs for Marine Habitat Mapping in Context with Biodiversity and Ecosystem-Based Management

When developing marine habitat maps, cartographic design and appropriate map scale (i.e. the combination of spatial grain, and spatial extent) must be determined. In addition, thematic scales also determine the utility of the map. A bathymetric map depicts only water depth (often based on acoustic data) and has a limited utility; map suites are more powerful and consist of bathymetric information displayed in conjunction with sonar backscatter strength and maps of sea floor surficial geology (Todd and Kostylev, 2000). Temporal scales 
also apply to marine habitat maps, given the value of time-series maps to support the EBM elements of "monitoring” and "adaptive management." A central question, therefore, is how to determine appropriate spatial, thematic, and temporal scales when designing marine habitat maps for EBM?

Technological mapping capabilities are continuously improving, and it is sometimes all too easy to let technology drive the methods of mapping habitats. This is also a potential problem with classification systems (see Parsons and Wand, 2008). In terrestrial habitat mapping, satellite and aircraft sensors are used in conjunction with field data to determine land cover, often discriminating vegetation types which in turn can be used to model the potential presence of vertebrate species. A common source of error is an inadequate model of the relationship between remotely-sensed spectral reflectance and actual land cover types that have ecological relevance. In marine systems, a similar problem exists with associating particular marine habitats with classifications based on remote sensing technologies, such as multibeam sonar acoustic mapping of the sea floor. Marine habitat classification systems should be robust enough to work independently of minor changes in evolving remote sensing technologies and they should function at multiple spatial grains, along with a hierarchical range of thematic resolutions (see also Greene et al., 2007, and Valentine et al., 2005). It is natural to strive to use the best available technology, but intelligent choices (guided by EBM criteria) regarding for example habitat classification design or tradeoffs between spatial resolution and mapping area can help us remain science-based rather than technology-driven.

In addition to ever-changing technologies and modeling capabilities, MHM must also respond to changes in conservation targets and policy priorities. ICES recently adopted a new fiveyear Science Plan (ICES, 2008), to anticipate and support new needs for scientific advice. 
This proactive realignment is needed to support requests for advice on ecosystems issues, as presented by the European Commission, the Oslo-Paris (OSPAR) Commission for North-East Atlantic, and other international regulatory authorities. Notably amongst the high-priority topics identified by ICES, most of them require an ecosystem approach and will be facilitated by MHM. These priorities include:

- Marine spatial planning, including the effectiveness of management practices, and its role in the conservation of biodiversity;

- Biodiversity and the health of marine ecosystems;

- Sensitive ecosystems (deep-sea coral, seamounts, Arctic) as well as rare and datapoor species;

- Contributions to socio-economic understanding of ecosystem goods and services, and forecasting of the impact of human activities;

- The role of coastal zone habitat in population dynamics of commercially exploited species;

- Influence of development of renewable energy resources (e.g. wind, hydropower, tidal and wave) on marine habitat and biota;

- Population and community level impacts of contaminants, eutrophication, and habitat changes in the coastal zone;

- Impacts of fishing on marine ecosystems;

- Climate change processes and predictions of impacts; and

- Introduced and invasive species, their impacts on ecosystems and interactions with climate change processes. 
Each of these priorities includes a strong spatial component. Each can benefit from GIS-based spatial modeling which is in turn well assisted by habitat mapping. For example, mapping of deep-sea corals is a logical early step in their management. Modeling the spatial distribution and health of multiple habitat types helps us to quantify incremental habitat degradation resulting from combinations of harvest pressures. Also, spatial patterns of point and non-point source contaminant release can be mapped, and analyzed in conjunction with marine habitat maps. We do not suggest that MHM is an end-all solution to each of these priorities; they will require many interdisciplinary collaborations and analysis types. We do however propose that MHM will be increasingly important to address these pressing management issues.

Adaptive management, as a fundamental EBM element (see EBM specific element six), specifically calls for a flexibility that must be supported by MHM. Another EBM elementorganizational change (EBM specific element eight)-also allows for transitions in policy. One way to ensure that marine habitat maps have maximum value is to design the maps to specifically support broad-based biodiversity assessment and analysis, which along with social and economic considerations can guide EBM toward specific management strategies (Figure 1). Producing habitat maps with singular, more restrictive goals in mind - marine protected areas for example - is less adaptable, less suitable for data synthesis, and likely to result in habitat map data of reduced value.

Changes in management goals and policy objectives are influenced by shifts and advances in the methodologies of MHM and EBM, and vice-versa. In the past, marine management and science have been predominately focused on single species indicators (McLeod et al., 2005). While such research is important - providing a detailed understanding of how a certain species interacts with their environment - knowledge of a single species does not in itself 
answer the broad questions of ecosystem sustainability that marine managers are faced with now. Resource managers today are not only interested in the management and conservation of single species, but are also required to work with a hierarchy of multiple targets to achieve precision (a focused scope of interest) and broader, more inclusive relevance (Figure 3). This does not mean that "less relevant” research such as single species investigations are not important; indeed these projects are prerequisites for the development of general studies.

From the biological perspective dealing with species habitats and communities, MHM is more inclusive than single species research and similar indicators, but less inclusive generally than biodiversity studies and EBM. One way to visualize this is to place MHM and EBM as transition phases within the continuum of applied research elements that covers species, communities, ecosystems, and human values (Figure 3, italic text). From this perspective, MHM is well positioned to integrate a series of basic indicators and present a spatiallyexplicit data synthesis of habitat conditions that can be used for modeling and analysis of biodiversity and ecosystem level management.

Some pioneering examples of MHM which have been strategically positioned to transition to "high-relevance" biodiversity assessment already exist. Recent investigations (Noji et al., 2008) in the U.S. Gulf of Maine exemplify how discrete data can be aggregated across thematic scales through modeling to help identify conservation targets. Data on sediment grain size, wave height, suspended chlorophyll, mixed layer depth, bottom currents, bottom temperature, and bottom salinity were used in a model modified from Kostylev et al. (2005) to describe the benthic habitats in terms of scope for growth and mechanical disturbance. For example, a portion of Georges Bank (indicated by an arrow in Figure 4A) is characterized by large scope for growth and moderate disturbance (Figure 4B). Scope for growth and 
disturbance can also be presented together using a habitat template matrix to map habitat types according to these two properties. A map of these habitat properties can be used to predict usage by biota including managed fish species such as Atlantic cod (Gadus morhua) (Figure 4C). The importance of habitat types for recruitment of fish is an important consideration for managers establishing marine managed areas.

In the context of EBM biodiversity is a multi-dimensional complex of structural, functional, and compositional elements occurring over a range of spatial and temporal scales (Figure 5). Following such a biodiversity template, marine habitat maps can logically inform users on a range of key biodiversity elements such as functional disturbances, habitat structure and physiognomy, and habitat components associated with species and community composition. The biodiversity template thus serves as a checklist for data elements (or data surrogates) included or omitted from the habitat maps and management goals.

\section{III) Conclusions}

Marine management based on ecosystem level processes is a daunting task but, an important responsibility for us and future generations. Such management programs must take into consideration multiple scientific, social, and cultural priorities and data, and it is sometimes difficult to make the jump from focused research projects to ecosystem-level management actions. In this paper, we have drawn from both the terrestrial and marine ecological sciences to re-visit the ten essential components of EBM and show how each of these is directly supported by MHM. By directly positioning the science of MHM to support biodiversity assessment and EBM, a focusing of research priorities is suggested, and we gain a useful perspective on marine EBM progress. 
Designing a survey program to conduct MHM in support of EBM calls for careful consideration of a series of critical design parameters. Aside from spatial, thematic, and temporal scale considerations (represented in Figure 5), pitfalls in classification design can lead to technology-driven approaches which may be ill-suited to work with the range of elements desirable in marine habitat maps.

MHM, biodiversity analysis, and EBM are best designed as flexible tools, resulting in datasets suitable for synthesis and adaptive management appropriate for use by multiple agencies and IGO’s. A powerful mechanism to preserve flexibility in habitat map products is to tailor the map applications for compatibility with biodiversity theory, allowing biodiversity to act as a bridge to allow habitat data to be used in support of EBM. In this sense, MHM, biodiversity analysis, and EBM are sequential. In practice, many management decisions are not made this way due to (for example) the need to act on a decision quickly. The steps from basic indicators (species) to EBM are however a useful target, helpful in prioritizing research funding to better understand the range of conservation targets for management.

By outlining the linkages between classification systems, MHM, biodiversity, and EBM, we have identified a series of compelling reasons to build on existing MHM programs worldwide. We have also offered guidelines for improving the science of MHM, in order to build a stronger theoretical base to support and guide future MHM and EBM developments. 


\section{References:}

AIDEnvironment, National Institute for Coastal and Marine Management/Rijksinstituut voor Kusten Zee (RIKZ) and Coastal Zone Management Centre the Netherlands. 2004. Integrated Marine and Coastal Area Management (IMCAM) approaches for implementing the Convention on Biological Diversity. CBD Technical Series no. 14. Montreal, Canada.

Andreasen, J. K., O'Neill, R. V., Noss, R. and Slosser, N. C. 2001. Considerations for the development of a terrestrial index of ecological integrity. Ecological Indicators, 1: 21-35.

Anonymous. 2001. Guidelines for the ecologically sustainable management of fisheries. Department of the Environment and Heritage, Commonwealth of Australia, Canberra.

Arkema, K. K., Abramson, S. C. and Dewsbury, B. M. 2006. Marine ecosystem-based management: from characterization to implementation. Frontiers in Ecology and the Environment, 10: 525-532.

Association of Fish and Wildlife Agencies 2006. National Fish Habitat Action Plan. p. 28. Washington, D.C.

Callicott, J. B. 2000. Aldo Leopold and the foundations of ecosystem management. Journal of Forestry, 98: 5-13.

Christensen, N. L., Bartuska, A. M., Brown, J. H., Carpenter, S., D'Antonio, C., Francis, R., Franklin, J. F., et al. 1996. The report of the Ecological Society of America committee on the scientific basis for ecosystem management. Ecological Applications, 6: 665-691.

Cogan, C. B. and Rachold, V. 2007. Second International Conference on Arctic Research Planning (ICARP II) Science Plan on Arctic Coastal Processes. In Arctic Research: A Global Responsibility. Ed. by S. Bowden, R. W. Corell, S. J. Hassol and C. Symon. McCallum Printing Group, Copenhagen, Denmark.

Coggan, R., Curtis, M., Vize, S., James, C., Passchier, S., Mitchell, A., Smit, C. J., et al. 2005. MESH (Mapping European Seabed Habitats): Review of standards and protocols for seabed habitat mapping. Joint Nature Conservation Committee (JNCC) Peterborough, UK. 192 pp.

De Young, C., Charles, A. and Hjort, A. 2008. Human dimensions of the ecosystem approach to fisheries: an overview of context, concepts, tools and methods. FAO Fisheries Technical Paper. No. 489. No. 489. Rome. 152 pp.

Ehler, C. N. and Douvere, F. 2007. Visions for a Sea Change. Report of the First International Workshop on Marine Spatial Planning. In Intergovernmental Oceanographic Commission and Man and the Biosphere Programme. IOC Manual and Guides, 46: ICAM Dossier, 3. UNESCO, Paris.

European Parliament 2008. Directive 2008/56/EC of the European Parliament and of the Council of 17 June 2008 establishing a framework for community action in the field of marine environmental policy (Marine Strategy Framework Directive). Official Journal of the European Union, L: 19-40.

FAO. 1995. Code of Conduct for Responsible Fisheries. Food and Agriculture Organization of the United Nations. Rome. 41 pp.

FAO. 2008. Fisheries management. 2. The ecosystem approach to fisheries. 2.1 Best practices in ecosystem modelling for informing an ecosystem approach to fisheries. FAO Fisheries Technical Guidelines for Responsible Fisheries. No. 4, Suppl. 2, Add. 1. Rome. 78 pp. 
Garcia, S. M., Zerbi, A., Aliaume, C., Do Chi, T. and Lasserre, G. 2003. The ecosystem approach to fisheries. Issues, terminology, principles, institutional foundations, implementation and outlook. FAO Fisheries Technical Paper. No. 443 . Rome. 73 pp.

Greene, H. G., Bizzarro, J. J., O'Connell, V. M. and Brylinsky, C. K. 2007. Construction of digital potential marine benthic habitat maps using a coded classification scheme and its application. In Mapping the Seafloor for Habitat Characterization, pp. 141-155. Ed. by B. Todd and H. G. Greene. Geological Association of Canada, St. John's, Newfoundland, Canada.

Grumbine, R. E. 1994. What is ecosystem management? Conservation Biology, 8: 27-38.

Hardman-Mountford, N. J., Hirata, T., Richardson, K. A. and Aiken, J. 2008. An objective methodology for the classification of ecological pattern into biomes and provinces for the pelagic ocean. Remote Sensing of Environment, 112: 3341-3352.

Harris, P. T., Heap, A. D., Bryce, S. M., Porter-Smith, R., Ryan, D. A. and Heggie, D. T. 2002. Classification of Australian clastic coastal depositional environments based upon a quantitative analysis of wave, tidal, and river power. Journal of Sedimentary Research, 72: 858-870.

ICES. 2008. ICES Science Plan, 2009-2013. International Council for the Exploration of the Sea, Copenhagen, Denmark 14pp.

Karr, J. R. and Dudley, D. R. 1981. Ecological perspective on water-quality goals. Environmental Management, 5: 55-68.

Kostylev, V. E., Todd, B., Longva, O. and Valentine, P. C. 2005. Characterization of Benthic Habitat on Northeastern Georges Bank, Canada. American Fisheries Society Symposium, 41: $141-152$.

Larkin, P. A. 1996. Concepts and issues in marine ecosystem management. Reviews in Fish Biology and Fisheries, 6: 139-164.

Leopold, A. 1941. Wilderness as a land laboratory. Living Wilderness, 6: 3.

Leopold, A. 1949. A Sand County Almanac, Oxford University Press, New York.

Longhurst, A. 2003. The symbolism of large marine ecosystems. Fisheries Research, 61: 1-6.

Mattson, K. M. and Angermeier, P. L. 2007. Integrating human impacts and ecological integrity into a risk-based protocol for conservation planning. Environmental Management, 39: 125-138.

McLeod, K. L., Lubchenco, J., Palumbi, S. R. and Rosenberg, A. A. 2005. Scientific Consensus Statement on Marine Ecosystem-Based Management. Communication Partnership for Science and the Sea (COMPASS) http://compassonline.org/?q=EBM.

MESH (Mapping European Seabed Habitat). 2008. The MESH Blue Book. Joint Nature Conservation Committee Peterborough, UK. 23 p. pp.

Millennium Ecosystem Assessment 2005. Ecosystems and Human Well-being: Biodiversity Synthesis. World Resources Institute, 86pp, Washington, DC.

Murawski, S. A. 2007. Ten myths concerning ecosystem approaches to marine resource management. Marine Policy, 31: 681-690.

NASA 1968. Earthrise. pp. http://grin.hq.nasa.gov/ABSTRACTS/GPN-2001-000009.html. National Aeronautics and Space Administration.

Noji, T. T., Fromm, S., Fromm, S., Vitaliano, J. and Smith, K. 2008. Habitat Suitability Modeling using the Kostylev Approach as an Indicator of Distribution of Benthic Invertebrates. In ICES Annual Science Conference, p. 5. International Council for the Exploration of the Sea, Halifax, Nova Scotia, Canada. 
Noji, T. T., Snow-Cotter, S. A., Todd, B. J., Tyrell, M. C. and Valentine, P. C. 2004. Gulf of Maine Mapping Initiative: A Framework for Ocean Management. Gulf of Maine Council on the Marine Environment. 22 p. pp.

Norton, B. G. and Ulanowicz, R. E. 1992. Scale and biodiversity policy - a hierarchical approach. Ambio, 21: 244-249.

Parsons, J. and Wand, Y. 2008. A question of class. Nature, 455: 1040-1041.

Pew Oceans Commission 2003. America's Living Oceans: Charting a Course for Sea Change - A Report to the Nation. Pew Oceans Commission, Arlington, Virginia.

Pickrill, R. A. and Kostylev, V. E. 2007. Habitat mapping and national seafloor mapping strategies in Canada. In Mapping the Seafloor for Habitat Characterization, pp. 483-495. Ed. by B. Todd and H. G. Greene. Geological Association of Canada, St. John's, Newfoundland.

Porter-Smith, R., Harris, P. T., Andersen, O. B., Coleman, R., Greenslade, D. and Jenkins, C. J. 2004. Classification of the Australian continental shelf based on predicted sediment threshold exceedance from tidal currents and swell waves. Marine Geology, 211: 1-20.

Rapport, D. J. 1998. Biodiversity and saving the earth. Environmental Monitoring and Assessment, 49: 169-175.

Rees, H. L., Eggleton, J. D., Rachor, E. and Vanden Berghe, E. 2007. Structure and dynamics of the North Sea benthos. In ICES Cooperative Research Report No. 288., p. 258. International Council for the Exploration of the Sea, Copenhagen, Denmark.

Ruckelshaus, M., Klinger, T., Knowlton, N. and DeMaster, D. P. 2008. Marine ecosystembased management in practice: Scientific and governance challenges. Bioscience, 58: 5363.

Smith, S. J. 2006. Presentation and Review of the Benthic Mapping Project in Scallop Fishing Area 29, Southwest Nova Scotia. Proceedings Series 2006/047 Dept. Fisheries and Oceans Population Ecology Division, Bedford Institute of Oceanography Dartmouth, Nova Scotia. 50 pp.

Spalding, M. D., Fox, H. E., Allen, G. R., Davidson, N., Ferdaña, Z. A., Finlayson, M., Halpern, B. S., et al. 2007. Marine ecoregions of the world: A bioregionalization of coastal and shelf areas. Bioscience, 57: 573-583.

Todd, B. and Kostylev, V. E. 2000. New approaches to benthic habitat mapping integrating multibeam bathymetry and backscatter, surficial geology and sea floor photographs: a case study from the Scotian Shelf, Atlantic Canada. In ICES Annual Science Conference, 27-30 September, Bruges, Belgium. Bruges, Belgium.

Tudela, S. and Short, K. 2005. Paradigm shifts, gaps, inertia, and political agendas in ecosystem-based fisheries management. Marine Ecology-Progress Series, 300: 282-286.

U.S. Commission on Ocean Policy 2004. An Ocean Blueprint for the 21st Century: Final Report of the U.S. Commission on Ocean Policy. Washington, D.C.

U.S. Department of the Interior and U.S. Department of Commerce 2005. Memorandum of Understanding Between the U.S. Geological Survey of the U.S. Department of the Interior and National Oceanic and Atmospheric Administration of the U.S. Department of Commerce to Coordinate and Cooperate in Activities Involving Physical and Biological Sciences and Environmental Studies. p. 5 p.

United Nations Environment Programme 1992. Convention on Biological Diversity. http://www.cbd.int, Rio de Janeiro. 
Valentine, P. C., Todd, B. J. and Kostylev, V. E. 2005. Classification of marine sublittoral habitats with application to the northeastern North America region. In Benthic Habitats and the Effects of Fishing. American Fisheries Society Symposium 41, pp. 183-200. Ed. by P. W. Barnes and J. P. Thomas. American Fisheries Society, Bethesda, Maryland.

Vierros, M., Cresswell, I., Briones, E. E., Rice, J. and Ardron, J. 2008. [Draft Report] Global Open Oceans and Deep Sea-habitats (GOODS) bioregional classification p. 102. UNEP/CBD/SBSTTA/13/INF/19 Rome.

Young, O. R., Osherenko, G., Ekstrom, J., Crowder, L. B., Ogden, J., Wilson, J. A., Day, J. C., et al. 2007. Solving the crisis in ocean governance: Place-based management of marine ecosystems. Environment, 49: 20-32. 


\section{Tables and Figures}

Table 1. Five goals of EBM. Within the overall goal of sustaining ecological integrity over the long term, Grumbine (1994) identified five specific goals.

1. Maintain viable populations of all native species in situ.

2. Represent, within protected areas, all native ecosystem types across their natural range of variation.

3. Maintain evolutionary and ecological processes (i.e., disturbance regimes, hydrological processes, nutrient cycles, etc.)

4. Manage over periods of time long enough to maintain the evolutionary potential of species and ecosystems.

5. Accommodate human use and occupancy within these constraints. 
Table 2. Five elements of marine EBM. Modified from a scientific consensus statement presented by McLeod et al. (2005).

\section{WHAT Is ECOSYSTEM-BASED MANAGEMENT FOR THE OCEANS?}

Ecosystem-based management is an integrated approach to management that considers the entire ecosystem, including humans. The goal of ecosystem-based management is to maintain an ecosystem in a healthy, productive and resilient condition so that it can provide for the maintenance of biodiversity. Ecosystembased management differs from current approaches that usually focus on a single species, sector, activity or concern; it considers the cumulative impacts of different sectors. Specifically, ecosystem-based management includes five main elements.

1. EBM includes an emphasis on the protection of ecosystem structure, functioning, and key processes.

2. EBM is place-based in focusing on a specific ecosystem and the range of activities affecting it.

3. EBM explicitly accounts for the interconnectedness within systems, recognizing the importance of interactions between many target species or key services and other non-target species.

4. EBM acknowledges interconnectedness among systems, such as between air, land and sea.

5. EBM integrates ecological, social, economic, and institutional perspectives, recognizing their strong interdependences. 


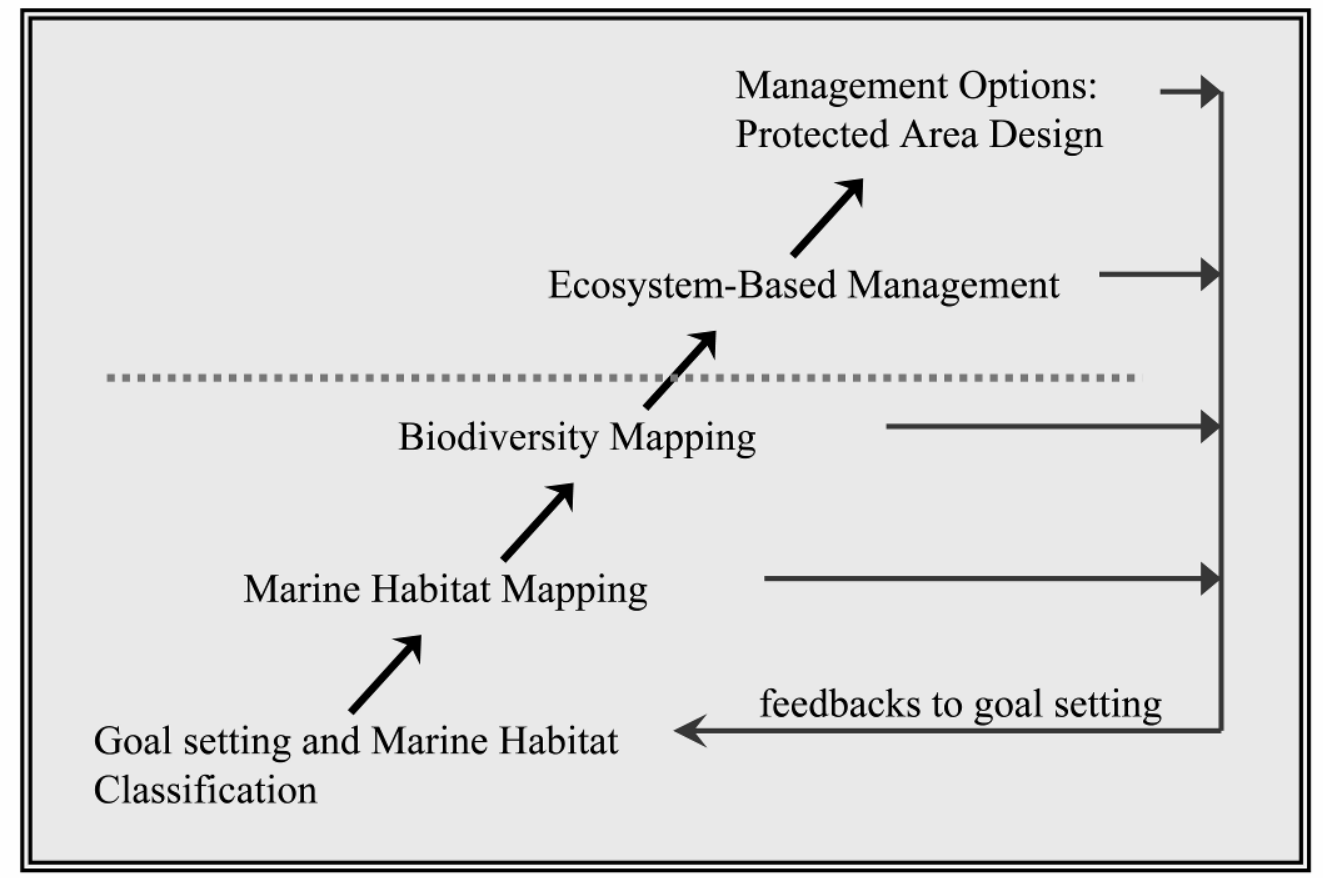

Figure 1. Marine habitat mapping as an early phase of ecosystem-based management. The dashed line in the middle represents a typical (and potentially problematic) division between project activity and institutional or governmental responsibility. Modified from Cogan and Noji (2007). 


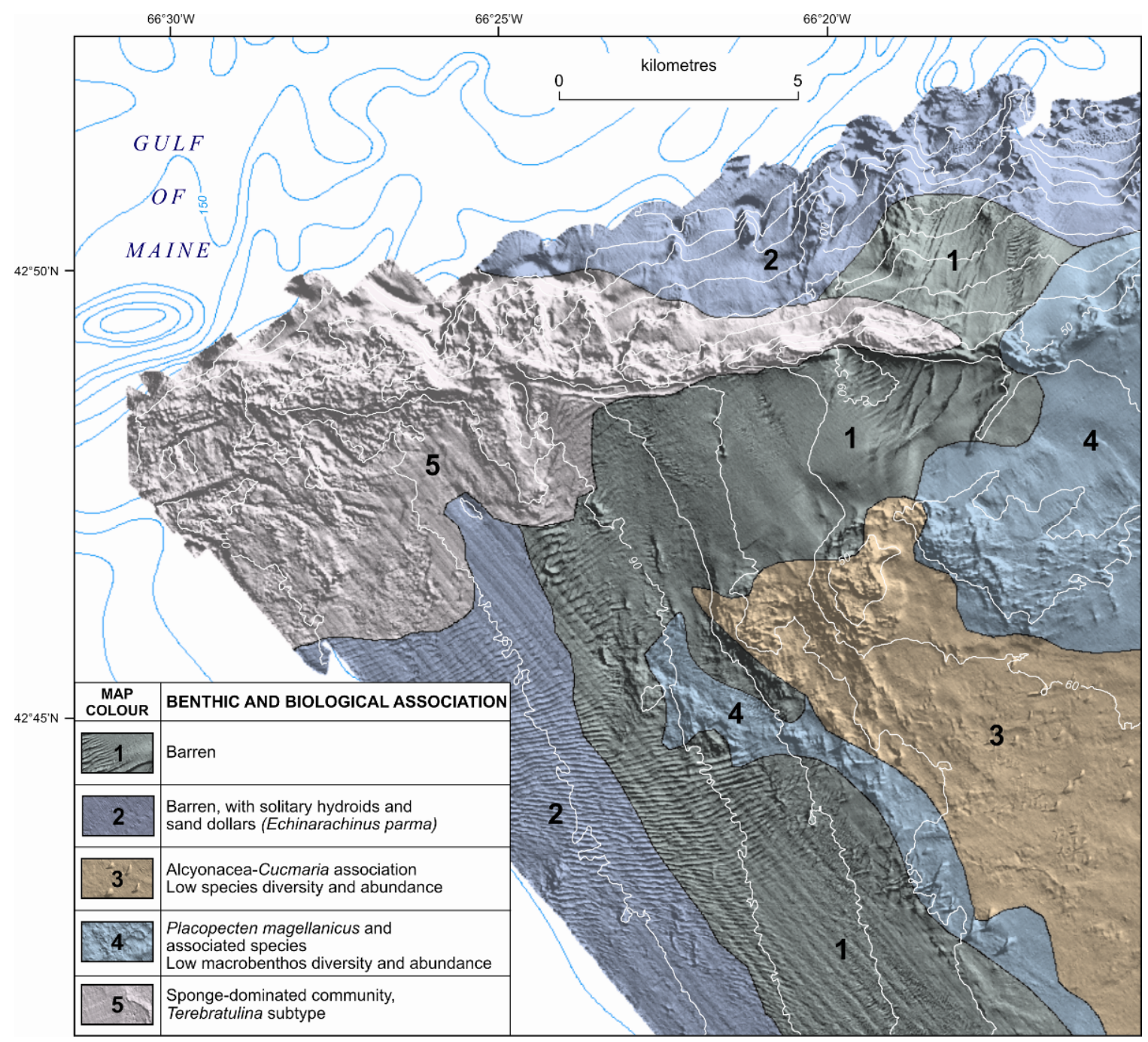

Figure 2. Enlarged segment from a marine habitat map designed for compliance with national map standards. This map depicts benthic habitat and sun-illuminated seafloor topography, in the region of Browns Bank, Scotian Shelf, offshore Nova Scotia. Modified from Todd et. al. (2006). 


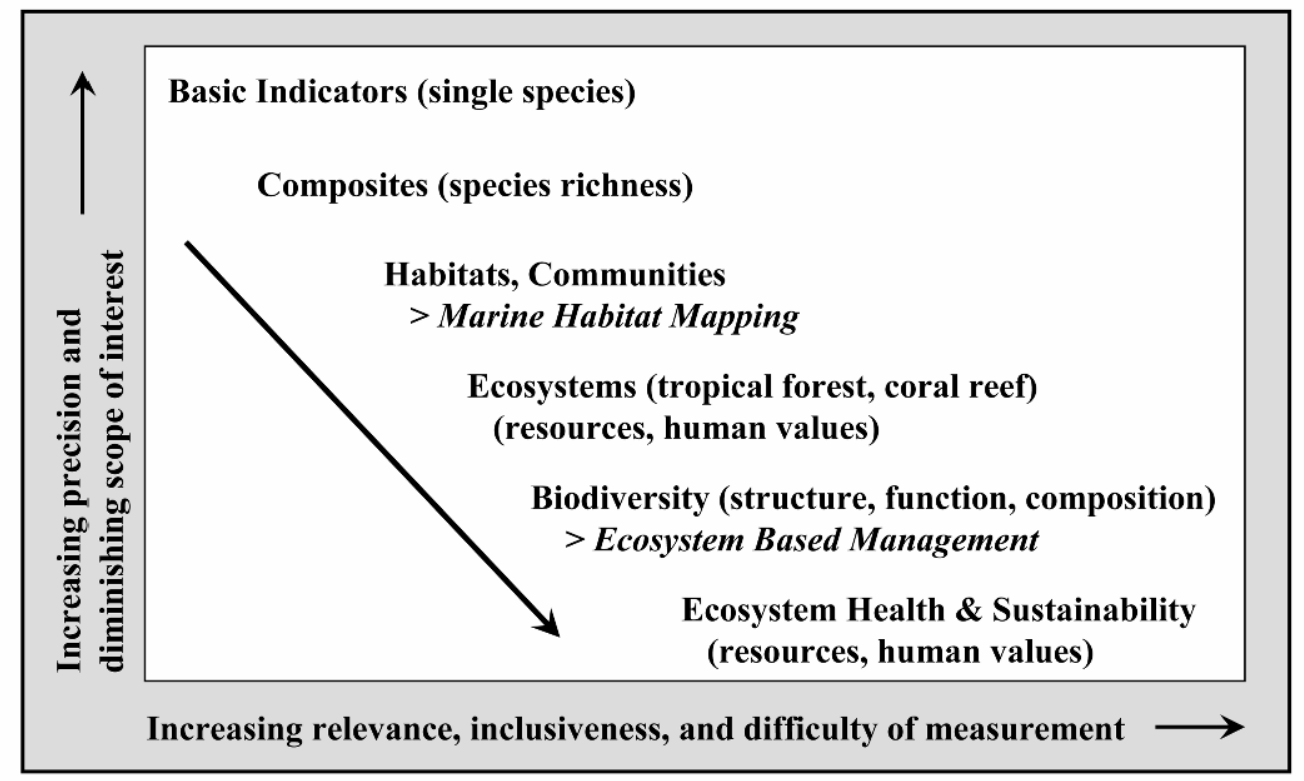

Figure 3. Thematic Scales \& Conservation Targets: Biodiversity in context with tradeoffs. Precision or diminishing scope of interest orders the vertical axis, while relevance and inclusiveness are measures along the horizontal. Narrow-scope research while important in its own right, synergistically supports increasing inclusiveness, a research trend indicated by the diagonal arrow to the lower right. Marine habitat mapping is approximately associated with the habitat community level, while ecosystem-based management is more closely associated with biodiversity analysis. Adapted from Costanza (1992) and Redford (2003).

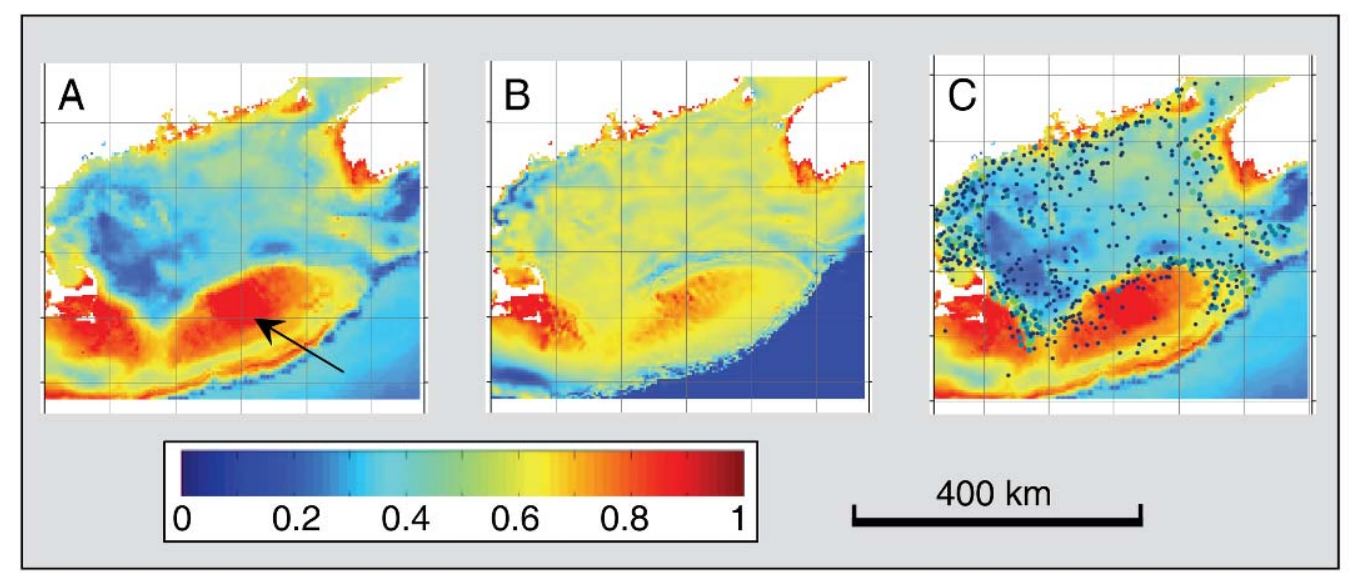


Figure 4. Scope for growth (4A) and disturbance (4B) of bottom habitats of the Gulf of Maine and Georges Bank (arrow) were modeled after Kostylev et al. (2005). Model results are color coded from low (in blue) to high (in red). Atlantic cod (Gadus morhua) distribution (4C) is also shown in relation to scope for growth. (Unpublished data courtesy of S. Fromm)

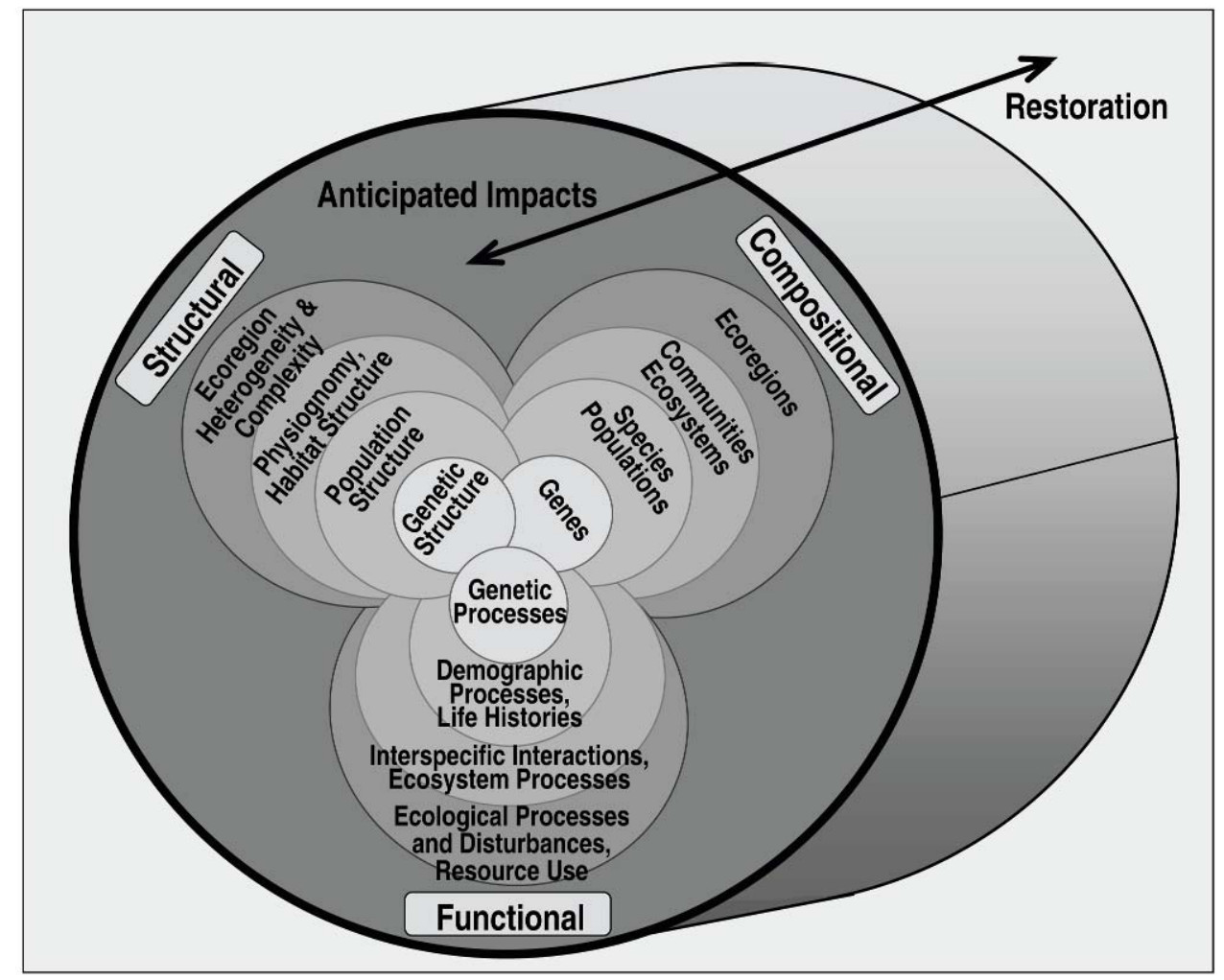

Figure 5. Biodiversity Elements. Structural, compositional, and functional elements of biodiversity, operating on different spatial and temporal scales. Restoration and anticipated impacts refer to past biodiversity states that may be changed by future restoration and future impacts in a temporally dynamic biodiversity system. Marine habitat mapping directly relates to several of these elements (see text). Figure adapted from Barkman (1978), Franklin and Cromack et al. (1981), Noss (1990), and Cogan and Noji (2007). 